\title{
Efficacy of used coffee grounds as larvicide against Aedes albopictus (Skuse, 1894) and Ae. aegypti Linné, 1762 (Diptera: Culicidae)
}

\author{
A. Drago $^{1^{*}}$ iD, S. Vettore ${ }^{1}$, S. Martini ${ }^{1}$ and M. Dutto ${ }^{2}$ \\ ${ }^{1}$ Entostudio S.r.l., Viale del Lavoro 66, 35020 Ponte San Nicolò (PD), Italy; ${ }^{2}$ Studio di Entomologia e Fitopatologia, Via \\ Papò 4, 12039 Verzuolo (CN), Italy; drago@entostudio.com
}

Received: 13 May 2021 / Accepted: 26 July 2021

(C) 2021 A. Drago et al.

\section{SHORT COMMUNICATION}

\begin{abstract}
Aedes albopictus and Aedes aegypti are two synanthropic, anthropophilic container-breeding mosquitoes. These species are very annoying, but are also vectors of dengue, chikungunya, yellow fever, Zika, and Usutu viruses, and other pathogens. Because these mosquitoes breed very close to humans, cheap homemade methods, as alternatives to commercial insecticides, could be important for their control. Coffee being a very common beverage, the grounds extracted from used coffee capsules have been tested for their larvicidal efficacy. The grounds were extracted with either $30 \mathrm{ml}$ or $70 \mathrm{ml}$ of $65-70{ }^{\circ} \mathrm{C}$ water. The content of one capsule was used as a unit dose to treat the quantity of water contained in a medium sized flowerpot tray. The test provided a clear indication that at this dosage, the used coffee capsules were completely ineffective at killing the larvae of Aedes species, so this method cannot be suggested to control these mosquitoes.
\end{abstract}

Keywords: mosquitoes, coffee, larvicide, Aedes albopictus, Aedes aegypti

\section{Introduction}

Aedes albopictus (Skuse, 1894) and Aedes aegypti Linné, 1762 are two species of relevant health importance due to their arbovirus vectorial capacity (Tsai and Teng, 2016). Only Ae. albopictus is to date widely and permanently established in Europe, where it is spreading by about 100 $\mathrm{km} /$ year (Kraemer et al., 2019). Ae. aegypti is currently present in Europe only on Madeira and in the coastal region of the Black Sea in southern Russia, Abkhazia and Georgia (Medlock et al., 2012), although it has been sporadically found in various European states following imports (Medlock et al., 2012). The ongoing climate change (increase in temperatures) together with the increasing of global trade could favour the expansion of these species. Ae. aegypti in particular, thereby increasing the risk of vector-borne disease outbreaks on the European continent (Liu-Helmersson et al., 2019).
The role of vectors, but above all the nuisance, makes the fight against these domestic mosquitoes necessary. The human population, in situations of non-infectious emergency, seems to give preference to the use of popular insecticide methods (authors' observation) the real efficacy of which is, in most cases, unknown. The internet has, surely, contributed to the wide circulation of information regarding possible alternative and biological methods for fighting mosquitoes. This led to the testing of different substances and materials including metallic copper (Della Torre et al., 1993), coffee grounds (Dieng et al., 2018; Ellias et al., 2015; Guirado and Bicudo, 2007; Laranja et al., 2003; Wiwanitkit, 2018) and tea extracts (Dieng et al., 2016). One advantage of the use of alternative insecticides would be to overcome the onset of resistance phenomena (Dieng et al., 2016). 
Given that coffee is a very common beverage in Europe (Landais et al., 2018) and therefore coffee grounds are widely available, we wanted to test their effect on the larval development of two species of Aedes known for their vectorial importance. The possibility of a mosquito control material / substance at very low cost, with little / no environmental impact, safe for humans and easily available, would represent a strong incentive for the implementation of control measures on private properties.

\section{Material and methods}

The study was performed using larvae of Ae. albopictus (colony originated from field eggs collection in Padua during years from 2011 to 2017) and Ae. aegypti (colony originated in 2015 by eggs from Biogents AG, Regensburg Germany) bred in a laboratory. These species breed in small containers in or near dwellings and are therefore commonly faced by inhabitants. Unlike other species that breed in sites like marshes, channels or lakes, the larval habitats of $A e$. albopictus and Ae. aegypti can be treated by private citizens on their ground.

The insects used for the test were bred in the laboratory, leaving them to lay their eggs on filter paper, which were then placed to hatch in dechlorinated water in the same room where the adults were reared. The larvae were fed with Altromin International ${ }^{\oplus}$ (Lage, Germany) rat chow until the pupal stage is reached, then were transferred into small containers and put into cages to complete development. Ae. albopictus was reared in $50 \mathrm{~cm}$ side cubic cages at $25 \pm 1^{\circ} \mathrm{C}$ and $50 \pm 5 \%$ of $\mathrm{RH}$ while Ae. aegypti was reared in identical cages but at $27 \pm 1{ }^{\circ} \mathrm{C}$ and $80 \pm 5 \%$ of RH. The photoperiod lasted 12 hours at a solar spectrum artificial light of 6,000 $\mathrm{K}$ and 300 lux intensity. The adults were fed with a $10 \%$ sugar solution and twice a week bovine blood was supplied through a Hemotek ${ }^{\oplus}$ system (Blackburn, UK).

To perform the test capsules of the brand Lavazza Bourbon Gustoso, a blend of a mix of Robusta coffee (Coffea canephora) and Arabica coffee (Coffea arabica) from Africa and South-East Asia, were used. They were extracted with a domestic coffee machine ('A Modo Mio' - Lavazza, Turin, Italy), operating at $65-70^{\circ} \mathrm{C}$. Because across Europe coffee is made 'strong' or 'light', two different extractions were applied, making 30 or $70 \mathrm{ml}$ of coffee beverage with one capsule. Because with a longer extraction, less caffeine remains in the coffee grounds, the dosage ' $70 \mathrm{ml}$ ' has to be considered as lower than the dosage ' $30 \mathrm{ml}$ '. As soon as the capsules were used, they were stored in a fridge at $3-4{ }^{\circ} \mathrm{C}$ until the test was performed, no more than 7 days later.

Groups of 20 larvae (L1), taken 24 hours after hatching, were placed in food grade polypropylene (PP) containers (Ø $86 \mathrm{~mm}$, h $120 \mathrm{~mm}$ ), with $430 \mathrm{ml}$ of tap water that had previously been stored in the open for 24 hours to permit chlorine to evaporate. As soon pupae appeared, a mosquito mesh was used to cover the container to avoid emerging adults flying away. This quantity of water was chosen because it is the capacity of a medium sized flower pot tray, the most typical domestic breeding site. The larvae were fed $0.04 \mathrm{~g}$ of rat food per day.

Treated replicates $(n=3)$ and control replicates $(n=3)$ were set up for each dosage and each target species. For each replicate $14.0 \mathrm{~g}$ of wet used coffee grounds (UCG) (corresponding to $31.5 \mathrm{mg} / \mathrm{ml}$ ) were added immediately before the introduction of the larvae. Coffee capsules contain around 7 grams of dry coffee but they almost double in weight because of the water adsorbed during extraction. The 14 grams of coffee grounds used per replication, therefore correspond to the quantity of coffee contained in a used capsule or pod. The coffee powder was taken from the capsules and inserted into filter bags (like the ones used for tea) before placing in the water containers, to facilitate observation of the larvae. An empty tea filter was inserted in each control replicate.

The test was performed in a room at $27.0 \pm 1{ }^{\circ} \mathrm{C}$ and $80 \pm 5 \%$ of R.H., the temperature of the water in the containers was $25.5 \pm 1{ }^{\circ} \mathrm{C}$. The containers were checked every 24 hours. At each assessment the emerged adults were counted and then removed by means of an entomological aspirator.

The test was concluded when live larvae or pupae were no longer present. Mortality was calculated using Abbott's formula (Abbott, 1987). Because the different dosages were tested at different times during 2020, for each species and dosage, specific control replicates were run contemporarily.

\section{Results}

The results are expressed as percentage of larval mortality or emerged adults (complementary value). The results are shown in Table 1.

Table 1. Larval mortality of Aedes albopictus and Aedes aegypti for the two coffee ground dosages.

$\begin{array}{llll}\text { Species } & \text { Dosage } & \begin{array}{l}\text { Mean larval } \\ \text { mortality (\%) }\end{array} & \begin{array}{l}\text { Emerged } \\ \text { adults (\%) }\end{array} \\ \text { Ae. albopictus } & 30 \mathrm{ml} \text { (control) } & 5 & 95 \\ & 30 \mathrm{ml} \text { (treated) } & 3.3 & 96.7 \\ & 70 \mathrm{ml} \text { (control) } & 1.7 & 98.3 \\ \text { Ae. aegypti } & 70 \mathrm{ml} \text { (treated) } & 6.7 & 93.3 \\ & 30 \mathrm{ml} \text { (control) } & 1.7 & 98.3 \\ & 30 \mathrm{ml} \text { (treated) } & 1.7 & 98.3 \\ & 70 \mathrm{ml} \text { (control) } & 1.7 & 98.3 \\ & 70 \mathrm{ml} \text { (treated) } & 2.5 & 97.5\end{array}$


The two-sample Mann-Whitney U test was used to compare values of emerged adults from the treated and control replicates (Table 2). This test is equivalent to a two-sample Wilcoxon rank-sum test. The test assumes that the observations are independent. There was no difference between adults emerged from control and treated samples, independently of the species or concentration.

\section{Discussion and conclusion}

The repellence of coffee versus Ae. albopictus females from the breeding sites and the inhibition of the embryonic development was shown by Satho et al. (2015). The capability of coffee extracts to reduce embryonic maturation as well as the shorter adult life span in dengue vectors were also proved (Dieng et al., 2016). Regarding the efficacy of the used coffee grounds as larvicide, the literature shows very different results. Guirado and Bicudo (2007) recorded a complete mortality of Ae. aegypti larvae but using a very high quantity of dry UCG $(300 \mathrm{mg} / \mathrm{ml})$ while Laranja et al. (2003) completely killed the larvae of the same species using only $50 \mathrm{mg} / \mathrm{ml}$.

The insecticidal action of coffee extracts or UCG is mainly driven by the caffeine, the dosage of $1.0 \mathrm{mg} / \mathrm{ml}$ of caffeine is sufficient to kill $100 \%$ of Aedes larvae (Laranja et al., 2003). The larvicidal efficacy of the exhausted coffee grounds is therefore strictly connected to their content of this alkaloid. Because caffeine is water-soluble the more water was used to produce the coffee drink, the less caffeine is present in the exhausted coffee grounds and therefore the preparation method of the beverage is very important. Brewed coffee, cold brew, instant coffee and espresso content have very different quantities of caffeine and therefore leave UCG with very different larvicidal efficacy. The plant species from where the coffee comes from is also very important. In general C. canephora (also known as 'Robusta') contains twice as much caffeine as $C$. arabica but this amount also depends on the different geographical origin (Jeszka-

Table 2. Mann-Whitney $U$ test values for emerged adults of Aedes albopictus and Aedes aegypti with the two coffee ground dosages.

$\begin{array}{llll}\text { Species } & \text { Dosage } & \text { Mean } \pm \text { sd } & P \text {-value } \\ \text { Ae. albopictus } & 30 \mathrm{ml} \text { (control) } & 2.46 \pm 4.39 & 0.653 \\ & 30 \mathrm{ml} \text { (treated) } & 2.42 \pm 5.67 & \\ & 70 \mathrm{ml} \text { (control) } & 1.90 \pm 2.11 & 0.1633 \\ & 70 \mathrm{ml} \text { (treated) } & 1.87 \pm 3.70 & \\ \text { Ae. aegypti } & 30 \mathrm{ml} \text { (control) } & 2.46 \pm 4.31 & 0.9898 \\ & 30 \mathrm{ml} \text { (treated) } & 2.46 \pm 4.89 & \\ & 70 \mathrm{ml} \text { (control) } & 2.19 \pm 4.52 & 0.5792 \\ & 70 \mathrm{ml} \text { (treated) } & 2.15 \pm 3.16 & \end{array}$

Skowron et al., 2016). The very different results found in the literature are therefore dependent on the many variables that affect the caffeine content.

As Laranja et al. (2003) and Derraik and Stanley (2005) showed, the use of UCG in nutrient-poor water can even create a more suitable environment for larval development thanks the availability of fatty acids, amino acids and other nutrients, as well as an increased growth of algae and bacteria.

The difficulty of standardisation and the very different results in terms of larval control suggest that the use of UCG shouldn't be advised because of the uncertainty of its efficacy. The use of partially effective methods can be very damaging when proved effective tools are available, while in specific conditions, when no better solutions are available, they could be helpful.

\section{Conflict of interest}

The authors declare no conflict of interest.

\section{References}

Abbott, W.S., 1987. A method of computing the effectiveness of an insecticide. Journal American Mosquito Control Association 3(2): 302-303.

Della Torre, A., Raineri, V. and Cancrini, G., 1993. Effetto del rame metallico sullo sviluppo larvale di Aedes albopictus: primi dati di laboratorio. Parassitologia 35: 51-53.

Derraik, J.G.B. and Stanley, D., 2005. The toxicity of used coffee grounds to the larvae of Ochlerotatus (Finlaya) notoscriptus (Skuse) (Diptera: Culicidae). Annals of Medical Entomology 14: 14-24.

Dieng, H., Ellias, S.B., Satho, T., Abang, F., Morales, R.E. and Morales, N.P., 2018. Response to the letter sent by Dr. Viroj Wiwanitkit entitled 'Coffee waste, vector control and dengue'. Environmental Science and Pollution Research 25: 32823-32825.

Dieng, H., Tan Yusop, N.S., Kamal, N.N., Ahmad, A.H., Ghani, I.A., Abang, F., Satho, T., Ahmad, H., Zuharah, W.F., Majid, A.H., Morales, R.E., Morales, N.P., Hipolito, C.N. and Noweg, G.T., 2016. Exposure of a dengue vector to tea and its waste: survival, developmental consequences and significance for pest management. Journal of Agricultural and Food Chemistry 64(18): 3485-3491.

Ellias, S.S., Dieng, H. and Ab Majid, A.H., 2015. Effects of different coffee extracts on the egg fertility and lifespan of dengue vectors (Aedes albopictus and Aedes aegypti) (Diptera: Culicidae). Serangga 20(1): 23-33.

Guirado, M.M. and Bicudo, H.E.M., 2007. Effect of used coffee grounds on larval mortality of Aedes aegypti L. (Diptera: Culicidae): suspension concentration and age versus efficacy. BioAssay 2: 5.

Jeszka Skowron, M., Sentkowska, A., Pyrzyńska, K., De Peña, M.P., 2016. Chlorogenic acids, caffeine content and antioxidant properties of green coffee extracts: influence of green coffee bean preparation. European Food Research and Technology 242: 1403-1409. 
Kraemer, M.U.G., Reiner, R.C., Brady, O.J., Messina, J.P., Gilbert, M., Pigott, D.M., Yi, D., Johnson, K., Earl, L., Marczak, L.B., Shirude, S., Davis Weaver, N., Bisanzio, D., Perkins, T.A., Lai, S., Lu, X., Jones, P., Coelho, G.E., Carvalho, R.G., Van Bortel, W., Marsboom, C., Hendrickx, G., Schaffner, F., Moore, C.G., Nax, H.H., Bengtsson, L., Wetter, E., Tatem, A.J., Brownstein, J.S., Smith, D.L., Lambrechts, L., Cauchemez, S., Linard, C., Faria, N.R., Pybus, O.G., Scott, T.W., Liu, Q., Yu, H., Wint, G.R.W., Hay, S.I. and Golding, N., 2019. Past and future spread of the arbovirus vectors Aedes aegypti and Aedes albopictus. Nature Microbiology 4: 854-863.

Landais, E., Moskal, A., Mullee, A., Nicolas, G., Gunter, M.J., Huybrechts, I., Overvad, K., Roswall, N., Affret, A., Fagherazzi, G., Mahamat-Saleh, Y., Katzke, V., Kühn, T., La Vecchia, C., Trichopoulou, A., Valanou, E., Saieva, C., Santucci de Magistris, M., Sieri, S., Braaten, T., Skeie, G., Weiderpass, E., Ardanaz, E., Chirlaque, M.D., Garcia, J.R., Jakszyn, P., Rodríguez-Barranco, M., Brunkwall, L., Huseinovic, E., Nilsson, L., Wallström, P., Bueno-deMesquita, B., Peeters, P.H., Aune, D., Key, T., Lentjes, M., Riboli, E., Slimani, N. and Freisling, H., 2018. Coffee and tea consumption and the contribution of their added ingredients to total energy and nutrient intakes in 10 European countries: benchmark data from the late 1990s. Nutrients 10(6): 725.
Laranja, A.T., Manzatto, A.J. and Bicudo, H.E.M., 2003. Effects of caffeine and used coffee grounds on biological features of Aedes aegypti (Diptera, Culicidae) and their possible use in alternative control. Genetics and Molecular Biology 26(4): 419-429.

Liu-Helmersson, J., Rocklöv, J., Sewe, M. and Brännström, Å., 2019. Climate change may enable Aedes aegypti infestation in major European cities by 2100. Environmental Research 172: 693-699.

Medlock, J.M., Hansford, K.M., Schaffner, F., Versteirt, V., Hendrickx, G., Zeller, H. and Van Bortel, W., 2012. A review of the invasive mosquitoes in Europe: ecology, public health risks, and control options. Vector Borne and Zoonotic Diseases 12(6): 435-447.

Satho, T., Hassan, A.A., Dieng, H., Abang, F., 2015. Coffee and its waste repel gravid Aedes albopictus females and inhibit the development of their embryos. Parasites \& Vectors 8: 272.

Tsai, P.J. and Teng, H.J., 2016. Role of Aedes aegypti (Linnaeus) and Aedes albopictus (Skuse) in local dengue epidemics in Taiwan. BMC Infectious Disease 16(1): 662.

Wiwanitkit, V., 2018. Coffee waste, vector control, and dengue. Environmental Science and Pollution Research 25(32): 32822. 